\title{
Reforma Psiquiátrica e a Política Nacional de Saúde Mental
}

\section{Psychiatric Reform and National Mental Health Policy}

\section{Reforma Psiquiátrica y la Política Nacional de Salud Mental}

Antonio José Costa CARDOSO ${ }^{1}$

Alexandre TRINO ${ }^{2}$

Marcelo PEDRA ${ }^{3}$

Pollyanna Pimentel de MEDEIROS ${ }^{4}$

Resumo: A Política Nacional de Saúde Mental busca consolidar um modelo assistencial em saúde mental aberto e de base comunitária. Constituída por dispositivos assistenciais diversos que devem funcionar de forma articulada, a Rede de Atenção Psicossocial (RAPS) corresponde à solução organizativa proposta para a implementação desse modelo assistencial. Esse texto pretendeu apoiar debate sobre a Política Nacional de Saúde Mental, Álcool e outras Drogas com os Analistas Técnicos de Políticas Sociais lotados no Ministério da Saúde (MS), na perspectiva de promover uma maior compreensão dos princípios e conceitos que a orientam enquanto projeto e processo de mudança nas práticas da Saúde Mental em resposta às necessidades da população, e refletir sobre os avanços e desafios que se apresentam no atual contexto de construção do Sistema Único de Saúde (SUS). Neste sentido, foi estruturado na perspectiva de responder a duas questões orientadoras: 1) Qual a racionalidade, a lógica, que sustentou a formulação e sustenta a implementação dessa Política? 2) Quais os dispositivos assistenciais que compõem a RAPS e qual é o papel do Centros de Atenção Psicossocial (CAPS) nessas redes?

Palavras-Chaves: Reforma Psiquiátrica; Política de Saúde Mental; Reabilitação Psicossocial; Redes de Atenção Integral em Saúde; Integralidade da Assistência.

Abstract: The National Mental Health Policy intends to consolidate a assistance model in mental health community-based. Consisting of assistive devices several which must function articulated, psychosocial care network (RAPS) corresponds to the organisational solution for the implementation of this assistance model. This text was intended to support debate on the National Policy on Mental Health, Alcohol and other Drugs with Technical Analysts in the Ministry of health (MS), with a

1 Médico, Doutor em Saúde Pública, Professor Adjunto do Departamento de Saúde Coletiva da Faculdade de Ciências da Saúde da UnB, coordenador da Graduação em Gestão em Saúde Coletiva. Contato: antoniojccardoso@gmail.com 2 Odontólogo, Mestre em Saúde Pública, Assessor Técnico da Coordenação Nacional de Saúde Mental, Álcool e Outras Drogas do Ministério da Saúde. Contato: alextrino@hotmail.com

3 Psicólogo, Assessor Técnico do Departamento de Atenção Básica do Ministério da Saúde. Contato: marcelopedra@ bol.com. br

4 Assistente Social, Mestre em Saúde Pública, Assessora Técnica da Coordenação Nacional de Saúde Mental, Álcool e Outras Drogas do Ministério da Saúde. Contato: pollypimenta@yahoo.com 
view to promoting greater understanding of the principles and concepts that guide while design and process of change in Mental health practices in response to the needs of the population, Reforma Psiquiátrica e a Política Nacional de Saúde Mental Psychiatric Reform and National Mental Health Policy Reforma Psiquiátrica y la Política Nacional de Salud Mental and reflect on the advances and challenges in the current context of constructing the Sistema Único de Saúde (SUS). In this sense, it was structured in order to answer two questions: 1) Which rationality, logic, supported the formulation and underpins the implementation of that policy? 2) Which assistive devices that make up the RAPS and what is the role of CAPS in these networks?

Key Words: Psychiatric reform; Mental health policy; Psychosocial rehabilitation; Continuum care networks in health; Integhrality assistance.

Resumen: La Política Nacional de Salud Mental busca consolidar un modelo de salud mental abierto y basado en la comunidad. Consta de dispositivos asistenciales varios que deben funcionar articulados, la red de atención psicosocial (RAPS) corresponde a la propuesta de solución organizacional para la implementación de este modelo de asistencia. Este texto fue destinado a apoyar el debate sobre la Política Nacional de Salud Mental, Alcohol y otras drogas con analistas técnicos del Ministerio de salud (MS), con miras a promover una mayor comprensión de los principios y conceptos que guían al mismo tiempo, el diseño y proceso de cambio en las prácticas de Salud Mental en respuesta a las necesidades de la población y reflexión sobre los avances y desafios en el contexto actual de la construcción del Sistema Único de Saúde (SUS). En este sentido, fue estructurado con el fin de responder a dos preguntas: 1) que la racionalidad, la lógica, apoyó la formulación y sustenta la aplicación de esa política? 2) ¿Cuáles aparatos que conforman el RAPS y ¿qué es el papel de las tapas en estas redes?

Palabras Clave: Reforma psiquiátrica; Política de salud mental; Rehabilitación psicosocial; Redes de atención integral en salud; Integridad de la asistencia.

\section{A Lógica da Atenção Psicossocial}

Embora irmã siamesa da Reforma Sanitária, a Reforma Psiquiátrica tem história e conceitos próprios1. No Brasil, é um processo que eclode a partir da segunda metade da década de 1970, fundada não apenas na crítica conjuntural ao subsistema nacional de saúde mental e ao caráter privatista da política de saúde do país, mas também, e principalmente, na crítica estrutural ao saber e às instituições psiquiátricas clássicas, no bojo de toda a movimentação político-social que caracterizou esta conjuntura de redemocratização ${ }^{2}$ A Política Nacional de Saúde Mental, Álcool e outras Drogas busca consolidar um modelo assistencial em Saúde Mental (SM) aberto e de base comunitária, cuja formulação foi inspirada em diversas experiências internacionais de mudança (pela superação do asilo, segregador e iatrogênico) que ocorreram no continente europeu e nos Estados Unidos da América no período posterior à Segunda Guerra Mundial. ${ }^{1}$ As principais experiências foram: 
1) A Psicoterapia Institucional francesa e as Comunidades Terapêuticas (que buscou construir a partir da Psicanálise um modelo discursivo/organizacional e fez prevalecer dispositivos grupais na rotina das comunidades), quando as transformações ainda eram restritas ao interior das instituições;

2) A Psiquiatria de Setor na França (influência de Michel Foucault e Robert Castel) e a Psiquiatria Comunitária norte-americana (desenvolvendo estruturas extra-hospitalares que evitassem internações prolongadas), que mudaram o enfoque da doença para a saúde mental;

3) E, correspondendo a propostas mais radicais de mudança, a Antipsiquiatria de Ronald Laing e David Cooper e a Psiquiatria Democrática de Franco Basaglia na Itália, esta centrada na luta contra o manicômio e pela revisão jurídico- normativa, visando à plena recuperação da cidadania pelos doentes mentais.

No auge da crise do modelo de assistência centrado no hospital psiquiátrico (denúncias de fraude no sistema de financiamento dos serviços, de abandono, de violência e dos maus tratos a que eram submetidos os pacientes internos), foi criado, em 1978, o Movimento dos Trabalhadores de Saúde Mental (MTSM), combinando reivindicações trabalhistas e um discurso humanitário pelos direitos dos pacientes psiquiátricos que ganhou repercussão na sociedade brasileira. ${ }^{1,3}$

Além do amadurecimento da crítica ao modelo privatista/asilar segregador, a década de 1980 assistiu a três processos igualmente importantes para a consolidação das características atuais do movimento da reforma: a ampliação dos atores sociais envolvidos no processo, a primeira iniciativa de reformulação legislativa e o surgimento de, ao menos, duas experiências institucionais bemsucedidas, marcos inaugural e paradigmático de uma nova prática de cuidados no Brasil: o Centro de Atenção Psicossocial (CAPS) Professor Luiz da Rocha Cerqueira, em São Paulo; e a intervenção na Casa de Saúde Anchieta, realizada pela administração municipal de Santos (SP), iniciando o que viria se constituir no exemplar Programa de Saúde Mental daquela cidade. 1,4,5

Organizado em torno dos Núcleos de Atenção Psicossocial (NAPS), o Programa de Saúde Mental de Santos operou duas grandes linhas de trabalho: a criação de uma rede de serviços substitutivos do "manicômio" (estruturas abertas, regionalizadas, com responsabilidade por toda a demanda da região, oferecendo cuidados 24 horas todos os dias, inclusive internação) e a promoção de uma atitude nova da sociedade em relação aos doentes mentais. ${ }^{1}$

Em 1987, a realização da I Conferência Nacional de Saúde Mental, reafirmando a falência do modelo asilar e impulsionando movimentos de reforma na área, demarcou o início da ambição de desconstruir o lugar da loucura no cotidiano das instituições e da sociedade ao instituir um novo lema para Reforma Psiquiátrica ("Por uma Sociedade sem Manicômios") e um novo horizonte de ação: preocupação não mais apenas com as macro-reformas e as instituições psiquiátricas, mas com o "cuidado", a cultura, o cotidiano e as mentalidades. Apesar da expressão "manicômio" ser reservado ao hospital judiciário, sua escolha pretendeu defender o fato de que não existe diferença 
entre essa instituição e outro hospital psiquiátrico qualquer. Não se trata, pois, de aperfeiçoar as estruturas tradicionais (ambulatório e hospital de internação), mas de inventar novos dispositivos e novas tecnologias de cuidado, o que exige rediscutir a clínica psiquiátrica em suas bases.

Embora só tenha sido aprovado em 2001 (Lei Federal 10.216), o Projeto de Lei que regulamenta os direitos da pessoa com transtornos mentais e a extinção progressiva dos manicômios apresentado pelo deputado Paulo Delgado em 1989 inaugurou a luta nos campos legislativos e normativos.

Em 1990, a Declaração de Caracas definiu princípios fundamentais para a Reforma Psiquiátrica nas Américas: 1) Respeito à dignidade e aos direitos humanos e civis das pessoas portadoras de transtornos mentais; 2) Reconhecimento da Atenção Primária em Saúde (APS) como espaço privilegiado para a garantia da atenção integral em SM; 3) Revisão do papel do hospital psiquiátrico e valorização de serviços comunitários; e 4) Práticas assistenciais interdisciplinares promotoras da autonomia e da permanência da pessoa portadora de transtornos mentais em seu meio.

Essa Conferência constituiu-se em uma referência fundamental para o processo de transformaçãodo modelo de atenção à saúde mental no Brasil: "marca o fim da trajetória sanitarista e o início de uma outra: a trajetória da desinstitucionalização ou desconstrução/invenção" trazendo ao cenário político novos atores de saúde mental: "são os loucos, os loucos pela vida"4.

Avançando nessa direção, foram traçadas as linhas principais da reorientação da saúde mental durante a II Conferência Nacional de Saúde Mental (CNSM) em 1992, cujas deliberações tiveram papel importante sobre os rumos da Reforma Psiquiátrica na década de 90, principalmente sobre a construção de uma rede de atenção à saúde mental, sobre a transformação da legislação e do direito à atenção integral e à cidadania, visando substituir progressivamente o modelo até então hegemônico de assistência psiquiátrica.

Entre 1990 e 2000, foram aprovadas em vários estados brasileiros leis que determinaram a substituição progressiva dos leitos psiquiátricos enquanto entraram em vigor as primeiras normas federais regulamentando a fiscalização dos hospitais psiquiátricos e a implantação de CAPS e Hospitais-Dia. Ao final deste período, havia 208 CAPS, mas 93\% dos recursos do MS para a Saúde Mental ainda eram destinados aos hospitais psiquiátricos.

Realizada em 2001, a III CNSM conferiu aos CAPS valor estratégico para a mudança do modelo de assistência, deliberou pela construção de uma política de saúde mental para os usuários de álcool e outras drogas e pelo apoio ao controle social como a garantia do avanço da Reforma Psiquiátrica no Brasil. A partir da aprovação da Lei Federal 10.216 (Lei Paulo Delgado) e da realização da III CNSM, foram criadas linhas específicas de financiamento pelo MS para os serviços abertos e substitutivos ao hospital psiquiátrico e mecanismos de fiscalização, gestão e redução programada de leitos psiquiátricos, privilegiando serviços de base comunitária.

Entre 2002 e 2012, a Reforma Psiquiátrica se consolidou como política do Estado brasileiro // Tempus, actas de saúde colet, Brasília, 8(1), 57-63, mar, 2014.

ISSN 1982-8829 
e o processo de desinstitucionalização de pessoas longamente internadas foi impulsionado pelo Programa Nacional de Avaliação do Sistema Hospitalar/Psiquiatria (PNASH/Psiquiatria), pelo Programa Anual de Reestruturação da Assistência Hospitalar Psiquiátrica no SUS (PRH), pela expansão de serviços substitutivos (CAPS e as Residências Terapêuticas) e pela criação do Programa De Volta para Casa. Mas os desafios continuam!

As Redes de Atenção Psicossocial (RAPS) Uma rede se conforma na medida em que são permanentemente articuladas instituições, associações, cooperativas e variados espaços das cidades.

Constituída por dispositivos assistenciais diversos que devem funcionar de forma articulada - Atenção Básica, Centros de Atenção Psicossocial (CAPS), Unidades de Pronto-Atendimento (UPA), leitos e enfermarias em hospitais gerais, Serviços Hospitalares de Referência, ambulatórios, Unidades de Atenção em Regime Residencial, Centros de Convivência e o Programa de Volta para Casa -, a Rede de Atenção Psicossocial (RAPS) corresponde à solução organizativa proposta para a implementação desse modelo assistencial em saúde mental no SUS.

O Decreto no 7.508, de junho de 2011, que regulamentou a Lei 8080/1990 e dispôs sobre a organização do SUS, o planejamento da saúde, a assistência e a articulação interfederativa a partir da consolidação de redes, define a Rede de Atenção à Saúde como o conjunto de ações e serviços de saúde articulados em níveis de complexidade crescente com a finalidade de garantir a integralidade da assistência à saúde.

Compartilhando dos princípios do SUS, a Rede de Atenção Psicossocial (RAPS) caracterizase por ser essencialmente pública, de base comunitária e por estar submetida a um controle social fiscalizador e gestor. $\mathrm{O}$ território é a designação não apenas de uma área geográfica, mas das pessoas, das instituições, das redes e dos cenários nos quais se desenvolve a vida comunitária.

A Rede de Atenção Psicossocial é constituída pelos seguintes componentes: I - Atenção Básica em Saúde; II - Atenção Psicossocial Especializada;III - Atenção de Urgência e Emergência; IV - Atenção Residencial de Caráter Transitório; V - Atenção Hospitalar; VI - Estratégias de Desinstitucionalização; e VI - Reabilitação Psicossocial.

Os CAPS são os articuladores estratégicos dessa rede e da política de saúde mental em um determinado território. Se diferenciam pelo porte, capacidade de atendimento, clientela atendida e organizam-se de acordo com o perfil populacional dos municípios. Para a implementação desse modelo assistencial em saúde mental aberto e de base comunitária, os CAPS passaram a ser estratégicos para a organização da Porta de Entrada e para a regulação da rede. Mas todos os dispositivos da RAPS precisam estar em total sintonia e sinergia no território. Os pontos de atenção estruturantes desta Rede (o CAPS e os dispositivos da Atenção Básica Equipes de Saúde da Família, Núcleo de Apoio ao Saúde da Família e equipes de Consultório na Rua) são fundamentais para a garantia do acesso ao usuário e também para a continuidade do cuidado. 


\section{COMENTÁRIOS FINAIS}

"Processo histórico de formulação crítica e prática que tem como objetivos e estratégias o questionamento e a elaboração de propostas de transformação do modelo clássico e do paradigma

da psiquiatria", a Reforma Psiquiátrica não fica restrita "à reformulação de serviços, ao rearranjo do aparato assistencial normativo, nem a reestruturação do texto jurídico que trata da matéria; não significa ainda a descoberta de novas técnicas, de uma escuta ou de uma terapêutica perfeitamente qualificada e competente, e por assim dizer, definitiva." ${ }^{2}$.

A questão colocada pela Reforma Psiquiátrica, embora privilegie o problema da assistência, não se restringe a ele, "pois o que está em pauta de maneira decisiva é delinear um outro lugar social para a loucura na nossa tradição cultural." 4 A Reforma Psiquiátrica pode ser compreendida, pois, como conjunto de iniciativas políticas, sociais e culturais, administrativas e jurídicas, que busca transformar a instituição e o saber médico-psiquiátrico, mas também as práticas sociais, abrangendo não só o campo assistencial, como também o conceitual, cultural e político, onde vêm sendo operadas várias transformações.

No campo assistencial, estão sendo criados, em todo o país novos serviços com propostas de tratamentos diferenciados dos serviços tradicionais, levandose em consideração a singularidade e as condições concretas de vida das pessoas que buscam ajuda.

No campo conceitual, a experiência de sofrimento mental é percebida também em sua complexidade e não mais pela objetivação da psiquiatria. E no campo cultural, multiplicam-se movimentos sociais, como as associações de familiares e de usuários, além de cooperativas e eventos para sensibilizar a sociedade para a forma como vêm sendo tratados os pacientes psiquiátricos e para as propostas da Reforma. O objetivo é possibilitar a construção de novas formas de convivência e transformar as tradicionais concepções de periculosidade, erro e desvio associadas à loucura.

Alguns aspectos, entretanto, ainda precisam ser fortemente considerados pelos empreendedores da Reforma Psiquiátrica: os aspectos subjetivos ligados a existência concreta do sujeito assistido; a redemarcação de um campo de práticas e saberes que não se restringe mais apenas à medicina e aos saberes psicológicos tradicionais; e a utilização do espaço comunitário como possibilidade de recurso terapêutico, e não a busca da sua "normalização". ${ }^{6} \mathrm{O}$ momento atual compreende, ainda, o desafio de avaliar a eficiência, eficácia e efetividades desses novos dispositivos assistenciais à luz dos conceitos e princípios propostos.

\section{REFERÊNCIAS BIBLIOGRÁFICAS}

1. PACHECO, J. G. Reforma Psiquiátrica, uma Realidade Possível - Representações Sociais da 
Loucura e a História de uma Experiência. Curitiba, Juruá, 2009.

2. AMARANTE, P. Uma aventura no manicômio: a trajetória de Franco Basaglia. Manguinhos, jul.- out., 1994:61-77.

3. BIRMAN, J. A Cidadania Tresloucada. In: Psiquiatria sem Hospício ( P. Amarante e B. Bezerra Jr., orgs.). Rio de Janeiro: Editora Relume Dumará, 1992.

4. Amarante, P. Loucos Pela Vida. A trajetória da Reforma Psiquiátrica no Brasil. Rio de Janeiro: Panorama/ ENSP, 1995.

5. TENÓRIO, F. A reforma psiquiátrica brasileira, da década de 1980 aos dias atuais: história e conceitos. História, Ciências, Saúde, Rio de Janeiro, vol. 9(1):25-59, jan.-abr., 2002.

6. KINOSHITA, R. T. Contratualidade e Reabilitação Psicossocial in: Reabilitação Psicossocial no Brasil. São Paulo, Hucitec, 1996:55-9.

Artigo apresentado em 06/01/13

Artigo aprovado em 10/03/14

Artigo publicado no sistema: 26/03/14 